29. Аниськин В.Н., Кочетова Н.Г. Формирование семиотической компетентности будущего специалиста // Вестник Самарского государственного технического университета. Серия: Психолого-педагогические науки. 2009. № 2. C. 8-14.

\title{
INDICATORS AND CONDITIONS OF FORMATION OF TECHNICAL UNIVERSITY BACHELORS PROFESSIONAL COMPETENCES IN THE COURSE OF MATHEMATICAL DISCIPLINES
}

(C) 2016

T.N. Kochetova, candidate of pedagogical sciences, associate professor of the Chair of Higher Mathematics and Applied Informatics

L.A. Ilina, doctor of economical sciences, head of the Chair of Industrial Economics and Production Management

O.U. Eremicheva, candidate of economical sciences, associate professor of the Chair of National and International Economics Samara State Technical University, Samara (Russia)

Abstract. A set of competences is the result of the modern professional school education. This set of competences is set by federal state educational standards of higher education. To achieve the required level of training is possible if the educational organization creates conditions for fundamental and at the same time professionally oriented education. It is necessary to develop tools and to describe evaluation procedures in order to describe the outcomes of education. The article describes the training of bachelors of «State and Municipal Management» and focuses on professional competence PC-7, which in accordance with the basic educational program of the Samara State Technical University, is to be formed by the disciplines comprising the basic part of the curriculum. To develop this competence one must master the method of investigating the phenomena and processes through the construction and study of their mathematical models. Application of this method reduces the solution of professional problems to mathematical modeling and subsequent study of the resulting model. To provide students with practice in resolving professional problems in the field of economy management, the authors developed a scheme of the use of real process modeling. Experience of teaching mathematical disciplines allowed the authors to outline organizational and pedagogical conditions, the implementation of which contributes to the formation of the competence in question. The effectiveness of the outlined conditions is proved experimentally. Indicators and performance criteria for the evaluation of the competence formation in the course of mathematics and basics of mathematical modeling of socio-economic processes are formulated.

Keywords: professional training, mathematical education, models of economic processes, the solution of professional problems by mathematical methods, organizational and pedagogical conditions of formation of competencies, indicators and criteria of formation of competences.

УДК 372.8

\section{СОДЕРЖАНИЕ И РАЗВИТИЕ БИОХИМИЧЕСКИХ ПОНЯТИЙ В ШКОЛЬНОМ КУРСЕ БИОЛОГИИ}

(C) 2016

И.В. Наливайко, кандидат педагогических наук, доцент кафедры биологии, экологии и методики обучения

Н.Г. Боброва, кандидат педагогических наук, доцент кафедры биологии, экологии и методики обучения Самарский государственный соииально-педагогический университет, Самара (Россия)

Аннотация. В статье раскрывается содержание биохимических понятий, составляющих школьный курс биологии, и показано их развитие на протяжении изучения всех разделов вышеназванного предмета: от растительного организма до общих закономерностей живой природы. Биология, как школьный предмет, является системой биологических понятий, которые развиваются в логической последовательности. Оперирование соответствующими понятиями показывает степень усвоения биологических знаний. Поэтому важна работа учителя по усвоению и развитию биологических понятий.

Изучение биохимических понятий включено в систему школьного курса биологии. Их можно классифицировать по сущности содержания, наряду с морфологическими, анатомическими и т.п. понятиями. Некоторые биохимические понятия относятся к группе общебиологических понятий, т.е. понятий о биологических закономерностях, относящихся ко всей живой природе. Это понятия: «обмен веществ и энергии», «питание», «дыхание», «выделение», «фотосинтез». Ряд биохимических понятий: «белки», «углеводы», «витамины», «ферменты» и ряд других являются специальными, так как изучаются в пределах определенного раздела.

В статье анализируется школьная программа и учебники биологии, что позволяет сделать вывод о том, что биохимические понятия формируются и развиваются на протяжении всего курса биологии с 6 по 11 класс. Существует преемственность в формировании и развитии данных понятий: сначала они являются специальными и изучаются как процессы, характеризующие жизнедеятельность растения; при рассмотрении процессов, происходящих в животных организмах, биохимические понятия становятся общебиологическими. В разделе «Общая биология» они вновь становятся специальными. Такая закономерность обосновывается логикой построения биологического материала.

Формированию биохимических понятий способствуют все виды словесных, наглядных и практических методов обучения биологии, причем роль последних особенно важна. Необходимо применение деятельностного под- 
хода при формировании биохимических понятий, т.к. одним из условий их правильного формирования является применение знаний в практической деятельности. Умения и навыки, усвоенные учащимися, являются показателем эффективности обучения, наряду с суммой предметных знаний.

Ключевые слова: развитие понятий, общебиологические понятия, биохимические понятия, специальные понятия, исследовательская деятельность, деятельностный подход, практические методы обучения, биология, биохимия, биологическая химия.

Центральным ядром системы научных знаний являются научные понятия [1]. Школьный курс «Биология» является системой основных биологических понятий, которые развиваются в логической последовательности. Система понятий определяется теми основами биологических наук, которые составляют учебный предмет: ботаника, зоология, анатомия, физиология, цитология, экология, биохимия и т.п. Поэтому освоение биологических знаний - это оперирование соответствующими понятиями [2].

И.Н. Пономарева отмечает: «Каждое понятие не может быть представлено учащимся сразу во всей его научной полноте. Последнее достигается при последовательном развитии содержания в соответствии с познавательными возможностями учащихся. Поэтому учителю необходимо знать, как происходит движение понятий из темы в тему, из курса в курс. Важно заранее предусмотреть, где понятия сливаются и обобщаются, переходят из одной группы в другую» [3, с. 301-302].

Теория развития понятий - одна из основных в методике преподавания биологии [4]. В основу теории развития понятий положено философское учение о познании, в котором выделяют эмпирические и теоретические уровни познания, выражающиеся в соответствующих понятиях. Эмпирические понятия - это знания, которые формируются на основе чувственного опыта. Теоретические понятия - это результат обобщения различных представлений $[5$, с. $31 ; 6$, с. 20].

Существует несколько подходов в классификации понятий. По объему содержания понятия делят: на простые и сложные. По степени общности выделяют специальные и общебиологические понятия. Биохимические понятия можно классифицировать по сущности содержания, наряду с морфологическими, анатомическими, экологическими, систематическими, цитологическими, эмбриологическими, гигиеническими и т.п. понятиями [6, с. 22-23].

Рассмотрим содержание и развитие биохимических понятий в процессе изучения биологии. Биохимия (биологическая химия или физиологическая химия) биологическая наука, которая располагается на стыке точных наук, изучающих физические и химические явления, и ряда биологических дисциплин. Биохимия изучает химический состав клетки, органов, тканей, жидкостей и целостного организма, химические реакции, проходящие в организме, обмен веществ и проявление их в биологических функциях $[7,8,9]$. Биохимия также использует понятия, формируемые в курсе общей химии (например, «реакция», «качественная реакция», «реакции осаждения», «минеральные (неорганические) и органические вещества» и т.п.).

Изучение биохимических понятий включено в систему школьного курса биологии, они входят в фундаментальное ядро содержания общего образования как один из документов сопровождения Федерального государственного образовательного стандарта (ФГОС) [10]. Последовательность биологических курсов: ботаника, зоология, человек, общая биология - определяет- ся доступностью учебного материала учащимися в зависимости от их возраста, подготовки и развития, необходимой преемственностью в содержании. Последовательность в изучении разделов имеет постепенно возрастающую сложность учебного материала. В тоже время все разделы не изолированы друг от друга. Взаимосвязь между ними проявляется, прежде всего, в формируемых понятиях.

Некоторые биохимические понятия относятся к группе общебиологических понятий, т.е. понятий о биологических закономерностях, относящихся ко всей природе, ко всем живым организмам. Это понятия: «обмен веществ и энергии», «катаболизм (диссимиляция)», «анаболизм (ассимиляция)», «питания», «дыхание», «выделение», «фотосинтез». Остальные биохимические понятия: «биоорганические вещества клетки: белки, углеводы, липиды, витамины, ферменты, гормоны», «макроэргические вещества», «гликолиз», «цикл Кребса», «незаменимые аминокислоты», «гликоген», «мочевина», «каталаза», «птиалин», «липаза» и другие являются специальными, так как изучаются в пределах определенного раздела.

Основополагающими факторами, влияющими на формирование системы понятийного аппарата, являются учебники, по которым учащиеся изучают дисциплины, организационные условия учебной деятельности, окружающая естественная и социально-культурная среда в которой развивается ученик [11].

Анализ школьной программы и учебников позволяет сделать вывод, что впервые учащиеся знакомятся с общебиологическими понятиями биохимического содержания («процессы жизнедеятельности», «питание», «дыхание», «выделение», «обмен веществ», «органические вещества», «микроэлементы», «фотосинтез», «АТФ», «углеводы (сахара)», «ферменты» при изучении растений, бактерий, грибов, лишайников.

Например, процессы питания, дыхания, обмена веществ первоначально трактуются как физиологические процессы, проходящие в растительном организме. Понятия формируются во взаимосвязи и трактуются следующим образом: «В процессе питания организм поглощает из внешней среды необходимые ему вещества и энергию, усваивает их, благодаря чему живет и увеличивается в размерах. Растения в процессе питания поглощают из почвы воду и растворенные минеральные вещества, а из воздуха - углекислый газ, из которых с помощью энергии света образуются органические вещества и используют их для построения своего тела, роста и развития. В процессе дыхания растительный организм потребляет кислород. При этом выделяется углекислый газ, образуются вредные для организма вещества. Каждому организму свойствен обмен веществ. При этом превращения веществ, поступивших в процессе питания и дыхания, протекающие в организме, обеспечивают его жизнедеятельность и постоянную связь с окружающей средой» [12, с. 19].

При изучении процессов жизнедеятельности клетки понятия «питание», «дыхание», «обмен веществ» трак- 
туются как биохимические процессы, доказывающие, что они свойственны как на клеточном, так и на организменном уровне. Питание клетки определятся как «ряд сложных химических реакций, в ходе которых вещества, поступившие в клетку из внешней среды (углекислый газ, минеральные соли, вода), входят в состав тела самой клетки в виде белков, сахаров, жиров, масел, азотных и фосфорных соединений» [12, с. 33]. Процесс дыхания клетки объясняется как химический процесс, дающий клетке энергию. Питание и дыхание клетки рассматриваются как взаимосвязанные процессы, которые обеспечивают обмен веществ - «главное проявление жизнедеятельности клетки и всего организма» $[12$, с. 33$]$.

В ряде школьных учебников различных авторских линий выделяется целая тема, посвященная изучению процессов жизнедеятельности, происходящих в растении. Дыхание определяется как сложный процесс, в ходе которого при распаде органических веществ высвобождается энергия, необходимая для процессов жизнедеятельности организма. Основными органическим веществом, участвующим в дыхательном процессе, являются углеводы (глюкоза). Понятие «дыхание» трактуется как биохимическое понятие посредством объяснения химических реакций, лежащих в основе, с указанием роли ферментов в этом процессе и места протекания в клетке [12, с. 109].

Сравнение процессов дыхания и фотосинтеза проводится с применением физиологических и биохимических процессов, происходящих на уровне клетки зеленого листа растения. Понятие «обмен веществ» при изучении растений, бактерий и грибов определяется «как совокупность протекающих в организме различных химических превращений, обеспечивающих рост и развитие организма, его воспроизведение и постоянный контакт с окружающей средой» [12, с. 111].

При изучении животных понятия «питание» и «дыхание» рассматриваются как физиологические процессы, связанные с функционированием всей поверхности тела или специализированных органов дыхания и питания. У животных изучение дыхания начинается на примере одноклеточных организмов, у которых оно происходит путем диффузии. При изучении кишечнополостных животных и типов червей, у которых нет специальных органов дыхания, речь идет о дыхании, происходящем через поверхность тела. При последующем изучении раздела ученики знакомятся с особенностями строения дыхательной системы различных представителей животного мира, усложнением процесса дыхания (жаберное, трахейное, легочное дыхание). Рассматривая процесс дыхания подчеркивается роль кислорода воздуха, необходимого для окисления веществ с образованием энергии, необходимой для прохождения процессов жизнедеятельности. Образующиеся вещества: вода, углекислый газ и некоторые другие должны удаляться из организма.

Питание у животных - это совокупность процессов, включающих поступление в организм, переваривания, всасывания и усвоения пищевых веществ, это составная часть обмена веществ. Организм получает химические соединения, которые используются для роста, жизнедеятельности, воспроизводства. Процесс питания протекает как в специализированных органоидах организма (одноклеточные животные), в замкнутой пище- варительной системе («Тип Кишечнополостные», «Тип Плоские черви»), в сквозной пищеварительной системе, формирующейся у представителей типа Круглые черви (в виде прямой трубки), в системе, имеющей специальные отделы или органы. При изучении состава пищеварительной системы вводится понятие «ферменты» как биологически активные вещества [13]. Более глубокого развития данных понятий при изучении животных не происходит.

В разделе «Человек» биохимические понятия вводятся с первых тем по изучению клетки, тканей, органов и систем органов человека. Данные понятия характеризуют общебиологическое понятие «клетка» через рассмотрение ее строения, химического состава, процессов жизнедеятельности. При формировании этого понятия применяются или впервые вводятся такие биохимические понятия как «аденозинтрифосфорная кислота - АТФ», «белки», жиры», «углеводы», «нуклеиновые кислоты - ДНК и РНК», «белки-катализаторы», «ферменты», «каталаза». Уточняется, что «обмен веществ между клеткой и внешней средой происходит через кровь и идет постоянно. Кровь приносит к клетке различные питательные вещества, кислород. Из этих питательных веществ образуются более сложные органические вещества (белки, жиры, углеводы), т.е. происходит синтез. Энергия, освободившаяся в результате биологического окисления (распада) органических веществ, идет на синтез молекулы АТФ, а потом используется на нужды клетки и организма. Продукты распада и окисления органических веществ - простые органические и неорганические соединения (вода, углекислый газ, мочевина и др.) - выводятся из клетки, а затем из организма [14, с. 16-18]. Здесь же предлагается провести лабораторную работу «Действие фермента каталазы на пероксид водорода».

В теме «Дыхательная система» вводится понятие «легочное дыхание» (развиваются представления о строении дыхательной системы организма человека, строении легких, газообмене в легких и нервногуморальной регуляции дыхания) и «тканевое дыхание» (отмечается роль крови в транспортировке кислорода ко всем клеткам организма и выведении углекислого газа. Подчеркивается, что кислород используется для биологического окисления, а выделившаяся энергия идет на процессы жизнедеятельности. Переносчиком кислорода в крови является гемоглобин - красный пигмент эритроцитов [14, с. 104].

Развитие понятия «питание» тесно связано с понятием «пищеварение» (тема «Пищеварительная система»). После изучения состава пищи и ее роли в обеспечении организма энергией и строительным материалом, изучения строения отделов пищеварительной системы, вводится понятие «пищеварение как процесс превращения питательных веществ в простые, растворимые соединения, которые легко всасываются в кровь и лимфу» [14, с. 125]. Рассматривая пищеварение в ротовой полости, желудке, тонком и толстом кишечнике, применяются биохимические понятия «белки», «жиры», «углеводы», «ферменты», «птиалин» («амилаза»), «пепсин», «слюна», «желудочный сок», «незаменимые аминокислоты», «гликоген», «мочевина», «минеральные соли», «витамины». Для изучения свойств и закрепления понятия «ферменты» предусматривается выполнение лабораторных работ «Действие ферментов 
слюны на крахмал», «Действие ферментов желудочного сока на белки».

Следует отметить, что именно в разделе «Человек» к словесным и наглядным методам формирования биохимических понятий добавляются практические методы, которые реализуются в форме лабораторных работ и предполагаю активную исследовательскую деятельность учащихся. «Исследовательская деятельность учащихся при изучении биологии - это деятельность по овладению методами исследования объектов живой природы с целью развития познавательного интереса, самостоятельности, интеллектуальных и практических умений. Она отражает методологический уровень содержания предмета и способствует знакомству учащихся с методами и формами научного познания» [15, c. 12]. Исследовательская деятельность школьников при изучении биологии может вестись в различных направлениях. В рамках этого вида деятельности можно организовать наблюдение или эксперимент. Внедрение эксперимента в преподавание биологии способствует не только установлению причинно-следственных связей между изучаемыми явлениями, но и формированию элементарных и сложных экспериментальных умений, относящихся к группе практических. Если речь идет о формировании биохимических понятий, то им будут соответствовать умения проводить биохимические реакции, выдвигать гипотезу, объяснять полученные результаты, выбирать оборудование, необходимое для проведения опытов. Исследовательская деятельность школьников может протекать индивидуально или коллективно. Причем последняя форма организации позволяет формировать не только универсальные учебные действия, но и метапредметные результаты обучения - умение работать в группе в качестве партнера по деятельности и в качестве лидера. Такая исследовательская коллективная деятельность должна протекать при соблюдении ряда методических условий [16].

Применение деятельностного подхода и включение учащихся в разнообразные виды учебно-познавательной деятельности способствует формированию и развитию биохимических понятий.

Развитию понятия «обмен веществ и энергии» отводится целая тема. В ней учащиеся узнают о стадиях обмена веществ (подготовительная и заключительная), о пластическом и энергетическом обмене, основном и общем обменах, о нормах питания человека, о роли витаминов в обеспечении обменных процессов [14].

В разделе «Основы общей биологии» (9 класс) многие общебиологические биохимические понятия становятся специальными, т.е. предметом изучения в ряде тем. В теме «Основы учения о клетке», но только обобщаются представления учащихся о химическом составе клетки, но применяются биохимические понятия «углеводы», «липиды», «белки», «нуклеиновые кислоты», «мономеры», «макромеры», «полимеры», «моносахариды», «дисахариды», полисахариды» и др. Впервые при изучении биологии формируется и развивается понятия «белок» через его строение (мономером белка является аминокислота), описание структур (первичная, вторичная, третичная, четвертичная), пространственной конфигурации (глобулярный белок), свойств белка (денатурация и ренатурация), описание функций (каталитическая) [17, с. 19]. В этой главе развивается понятие «нуклеиновые кислоты» (ДНК - дез- оксирибонуклеиновая кислота, РНК - рибонуклеиновая кислота) через описание строения мономеров нуклеиновых кислот (нуклеотиды, которые в свою очередь состоят из азотистых оснований аденин, гуанин, цитозин, урацил, тимин), строение полимера (одно- и двухцепочечная молекула), принципа построения (комплементарность), значение (молекулы ДНК хранят наследственную информацию, молекулы РНК участвуют в ее реализации) [17, с. 20-22].

Углубляются представления об обменных процессах. Понятие «обмен веществ и энергии» обозначается как «метаболизм - совокупность биохимических реакций, протекающих в клетке и обеспечивающих ее процессы жизнедеятельности». Вводится представление о двух сторонах обмена веществ «анаболизм (ассимиляция, пластический обмен) и катаболизм (диссимиляция, энергетический обмен) [17, с. 29-31].

При описании энергетического обмена рассматривается строение молекулы АТФ, указывается энергетическая емкость химических связей (однако, понятие «макроэргическая связь» не применяется). Пластический обмен раскрывается через вопросы биосинтеза белков и углеводов в живой клетке. Учащиеся знакомятся со схемой процесса биосинтеза: ДНК $\rightarrow$ РНК $\rightarrow$ белок. Вводятся понятия «транскрипция», «трансляция», «генетический код», «триплетность кода», отмечается роль нуклеиновых кислот ДНК, и-РНК, т-РНК и рибосом в процессе биосинтеза белка.

При рассмотрении вопроса биосинтеза углеводов происходит развитие понятия «фотосинтез»: более детально рассматривается строение хлоропластов, первая и вторая стадия фотосинтеза, приводится схема фотосинтеза, в которой отражается роль света в возбуждении электронов молекулы воды; участие ферментов НАДФ в переносе ионов водорода и электронов, образование молекул АТФ и реакции синтеза углеводов [17, c. 35-39]. В содержании темы раскрывается сущность процессов обмена энергией. Извлечение энергии из пищевых веществ осуществляется в клетке путем их расщепления и окисления в процессе дыхания. Такое дыхание называется «биологическим окислением» или «клеточным дыханием». Вводится представление об анаэробном и аэробном этапах биологического окисления, приводится схема процесса биологического окисления, отражающая процессы пищеварения, расщепления в бескислородных условиях, окисления в кислородных условиях. Конечными продуктами биологического окисления являются АТФ, вода и углекислый газ. Приводится химическая сторона процесса гликолиза, энергетический эффект рассматриваемых этапов [17, c. 39-42]. Необходимо отметить, что данная тема в сокращенном виде рассматривает сложные процессы пластического и энергетического обмена, применяется большое количество биохимический терминов без их глубокого анализа и раскрытия, что является достаточно трудным для усвоения учащимися 9-х классов.

В учебнике биологии для 10 класса понятие «обмен веществ и энергии» трактуется как свойство всех живых организмов, т.е. является общебиологическим. Обмен веществ и энергии не только совокупность химических реакций, реализующий связь организма с внешней средой, но и условие его жизни. «Обмен веществ и энергии поддерживает постоянство внутренней среды клеток и всего организма, позволяет восста- 
навливать его разрушенные структуры, способствует росту, развитию, сохранению высокоупорядоченного строения и жизнедеятельности клеток (организма)» $[18 ; 19$, с. 6$]$.

Построение учебного материала 10-11 класса линии И.Н. Пономаревой проводится по уровням организации живого: от биосферного, биогеоценотического через популяционно-видовой, организменный до клеточного и молекулярного [20]. Формирование биохимических понятий завершается в школьном курсе биологии в теме «Молекулярный уровень жизни». Происходит повторение и некоторое уточнение биохимических понятий: «макро- и микроэлементы», «углеводы», «липиды», «белки (протеины)», «ферменты», «нуклеиновые кислоты», «биосинтез», «фотосинтез», «гликолиз», «кислородная стадия аэробного расщепления», «витамины», «гормоны». Включаются новые биохимические термины и понятия «пируват (молочная кислота)», «белок-репрессор», «кофермент», «вазопрессин», «окситоцин», «кортикотропин», «простогландины», которые встречаются только в одном или двух параграфах учебника, т.е. являются локальными. Никаких лабораторных работ как способа формирования биохимических понятий не предусматривается.

Таким образом, понятия «микро- и макроэлементы», «питание», «пищеварение», «дыхание», «обмен веществ и энергии», «фотосинтез», являющиеся биохимическими понятиями, формируются и развиваются на протяжении всего курса биологии с 6 по 11 класс. Существует преемственность в формировании и развитии данных понятий: сначала они являются специальными и изучаются в как процессы, характеризующие жизнедеятельность растения; при рассмотрении процессов, происходящих в животных организмах биохимические понятия становятся общебиологическими. В разделе «Общая биология» они вновь становятся специальными. Такая закономерность обосновывается логикой построения биологического материала. Анализ содержания и развития биохимических понятий в школьном курсе биологии показал, что учебники линии И.Н. Пономаревой не включают такие понятия как «качественные реакции» (на белки, углеводы, липиды, продукты гидролиза нуклеопротеинов, витамины, гормоны, ферменты), «реакции осаждения» (белков), «активность фермента». А ведь данные понятия применяются при составлении заданий для регионального этапа Всероссийской олимпиады школьников и требуют их включения в процесс обучения биологии.

Проблема развития понятий, как в теории методики, так и в практике преподавания биологических предметов - одна из наиболее актуальных и сложных. Преподавание биологии за последние годы подверглось значительной перестройке, программы дополнялись и сокращались настолько, что возникла настоящая необходимость в определении системы знаний, наиболее существенных понятий основ наук, которые должны изучаться в школе. Необходимо применение деятельностного подхода в формировании понятий, т.к. одним из условий правильного формирования понятия является применение знаний в практической деятельности. Умения и навыки, усвоенные учащимися, являются показателем эффективности обучения, наряду с суммой предметных знаний.

\section{СПИСОК ЛИТЕРАТУРЫ:}

1. Усова А.В. Условия успешного формирования у учащихся научных понятий // Наука и школа. 2006. № 4. С. 57-59.

2. Ховрин А.Н. Понятие «обмен веществ и превращение энергии» как системообразующее в содержании раздела «Человек» курса биологии в обще образовательной школе // Вестник Московского городского педагогического университета. Серия: Естественные науки. 2012. № 1 (9). С. 106-110.

3. Пономарева И.Н., Соломин В.П. Экологическое образование в Российской школе: История. Теория. Методика: Учебное пособие / Под ред. В.П. Соломина. СПб.: Изд-во РГПУ им. А.И. Герцена. 415 с.

4. Пономарева И.Н., Соломин В.П., Сидельникова Г.Д. Общая методика обучения биологии: учеб. пособие для студ. пед. вузов / под ред. И.Н. Пономаревой. М.: Издательский центр «Академия», 2003. 272 с.

5. Матюшенко Е.Е. Методические основы формирования генетических понятий в профильном курсе биологии // Ярославский педагогический вестник. 2009. № 2. С. 31-34.

6. Семенов А.А., Боброва Н.Г., Глазкова Л.М. Вопросы теории и методики обучения биологии: Учебное пособие для студентов-заочников. Самара: Издательство СГПУ, 2003. 175 с.

7. Биологическая химия: Пособие-практикум для студентов биолого-химического факультета / Составители: Л.П. Наливайко, В.М. Астафьев, И.В. Наливайко. Самара: Изд-во СамГПУ, 2001. 116 с.

8. Филиппович Ю.Б., Ковалевская Н.И., Севастьянова Г.А. Биологическая химия: учеб. пособие для студ. высш. учеб. заведений / под ред. Н.И. Ковалевской. 3-е изд., испр. М.: Издательский центр «Академия», 2009. $256 \mathrm{c.}$

9. Учебно-исследовательские экспериментальные работы, задачи и упражнения по биохимии: Для студентов естественно-географического факультета / Сост. И.В. Наливайко, Л.П. Наливайко. Самара: Изд-во СамГПУ, 2008. 46 с.

10. Андреева Н.Д., Азизова И.Ю., Малиновская Н.В. Новые подходы к обучению биологии в образовательной школе в условиях ФГОС: Учебное пособие. СПб.: Изд-во «Свое издательство», 2015. 299 с.

11. Ахметова Л.В. Формирование понятийного аппарата учащихся при изучении естественно-научных дисциплин // Вестник Томского государственного педагогического университета. 2011. № 6. С. 155-160

12. Пономарева И.Н., Корнилова О.А., Кучменко В.С. Биология: Растения. Бактерии. Грибы. Лишайники: Учебник для учащихся 6 класса общеобразовательных учреждений / под ред. проф. И.Н. Пономаревой. М.: Вентана-Графф, 2010. 240 с.

13. Константинов В.М., Бабенко В.Г., Кучменко В.С. Биология: Животные: Учебник для 7 класса общеобразовательной школы / под ред. В.М. Константинова, И.Н. Пономаревой. М.: Вентана-Граф, 2013. 304 с.

14. Драгомилов А.Г., Маш Р.Д. Биология: Человек: Учебник для учащихся 8 класса общеобразовательных учреждений. М.: Вентана-Граф, 2007. 272 с.

15. Боброва Н.Г. Виды учебно-познавательной деятельности в обучении биологии: дидактическая и методическая характеристика // Самарский научный вестник № 2 (7). Самара: ПГСГА, 2014. С. 11-15. 
16. Боброва Н.Г. Аспекты применения технологии обучения в сотрудничестве при организации практической деятельности учащихся на уроках биологии // Научно-методический электронный журнал Концепт. 2014. № 7. С. 31-35.

17. Пономарева И.Н., Корнилова О.А., Чернова Н.М. Основы общей биологии: Учебник для учащихся 9 класса общеобразовательных учреждений / Под общ. ред. проф. И.Н. Пономаревой. М.: Вентана-Графф, 2013. $240 \mathrm{c}$.

18. Лисун Н.М. Формирование понятия «обмен веществ» в курсе общей биологии 10-11 класса: дис. ... канд. пед. наук (13.00.02 - теория и методика обучения и воспитания). Челябинск, 2011. $187 \mathrm{c}$.

19. Пономарева И.Н., Корнилова О.А., Лощилина Т.Е. Биология: 10 класс: базовый уровень учебник для учащихся общеобразовательных учреждений / Под общ. ред. проф. И.Н. Пономаревой. М.: Вентана-Графф, 2010. 224 c.

20. Пономарева И.Н., Корнилова О.А., Лощилина Т.Е., Ижевский П.В. Биология: 11 класс: базовый уровень: учебник для учащихся общеобразовательных учреждений / Под общ. ред. проф. И.Н. Пономаревой. М.: Вентана-Граф, 2013. 240 с.

\title{
THE CONTENT AND DEVELOPMENT OF BIOCHEMICAL CONCEPTS IN THE SCHOOL COURSE OF BIOLOGY
}

(C) 2016

\author{
I.V. Nalivayko, candidate of pedagogical sciences, associate professor \\ of the Chair of Biology, Ecology and Methods of Teaching \\ N.G. Bobrova, candidate of pedagogical sciences, associate professor \\ of the Chair of Biology, Ecology and Methods of Teaching \\ Samara State University of Social Sciences and Education, Samara (Russia)
}

\begin{abstract}
The article reveals the content of biochemical concepts constituting school biology course, shows their development during the study of all the units of the subject mentioned above: from the vegetable organism to the general laws of nature. Biology as a school subject is a system of biological concepts, developing in a logical sequence. The handling of the relevant concepts shows the degree of assimilation of biological knowledge. That is why the teacher's work on assimilation and development of biological concepts is so important.

The study of biochemical concepts is included in the school course of biology. They can be classified according to the nature of the content, along with morphological, anatomical concepts etc. Some biochemical concepts belong to the group of basic biological concepts, i.e. concepts about the biological regularities concerning with the whole wildlife. They are: «metabolism and interchange of energy», «nutrition», «breathing», «selection», «photosynthesis». A number of biochemical concepts such as «proteins», «carbohydrates», «vitamins», «enzymes» and some others are special, as they are studied within a specific section.

The article analyzes school curricula and textbooks on biology; it allows making a conclusion that biochemical concepts are formed and developed throughout the biology course from 6 to 11 grades. There is a succession in formation and development of these notions: at first they are special and are studied as processes characterizing the functioning of a plant; considering the processes occurring in animal organism, biochemical concepts become general. In the «General Biology» unit they become special again. Such regularity is substantiated by the logic of construction of biological material.

The formation of biochemical concepts is contributed to by all kinds of verbal, visual and practical methods of teaching biology, the role of the latter is particularly important. It requires the use of activity approach during the formation of biochemical concepts, because one of the conditions for their proper formation is the application of knowledge in practice. Skills acquired by students are the indicators of the effectiveness of education, together with the amount of subject knowledge.
\end{abstract}

Keywords: development of concepts, biological concepts, biochemical concepts, special concepts, research activity, an activity approach and practical training methods, biology, biochemistry.

УДК 378.147

\section{ПУТИ ОПТИМИЗАЦИИ ЮРИДИЧЕСКОГО ОБРАЗОВАНИЯ В РОССИИ}

(C) 2016

П.К. Рамазанова, кандидат филологических наук, доцент, заведующий кафедрой гуманитарных и социально-экономических дисциплин

3.А. Гаджиева, кандидат филологических наук,

доцент кафедры гуманитарных и социально-экономических дисциплин

Северо-Кавказский институт (филиал) Всероссийского государственного университета юстиичи в г. Махачкале, Махачкала (Россия)

\begin{abstract}
Аннотащия. В статье выявлены проблемы, которые возникают на этапе подготовки специалистов юридического профиля. Причем возросшее количество вузов не смогло оптимизировать, улучшить сложившуюся ситуацию. Авторы статьи анализируют причины ухудшения качества юридического образования. Предпринята попытка выявления пробелов в сфере юридического образования, т.к. только определение правильного диагноза болезни позволяет выбрать эффективное лечение. Для реформирования юридического образования необходимо привлекать представителей общественности, которые будут прослеживать процесс оптимизации вузов, налаживать контакты с факультетов с различными организациями. Необходимо предъявлять высокие требования к профессор-
\end{abstract}

